\title{
Numerical Solution of Nonlinear Large Strain Consolidation Based on Non-Darcian Flow
}

\author{
Xu-dong Zhao $\mathbb{D}$ and Wen-hui Gong \\ School of Civil Engineering \& Mechanics, Huazhong University of Science and Technology, Wuhan, 430074, China \\ Correspondence should be addressed to Xu-dong Zhao; zhaoxd@hust.edu.cn
}

Received 7 February 2019; Revised 10 April 2019; Accepted 16 May 2019; Published 27 May 2019

Academic Editor: Gregory Chagnon

Copyright (C) $2019 \mathrm{Xu}$-dong Zhao and Wen-hui Gong. This is an open access article distributed under the Creative Commons Attribution License, which permits unrestricted use, distribution, and reproduction in any medium, provided the original work is properly cited.

\begin{abstract}
In this paper, based on non-Darcian flow, the governing equation of 1D nonlinear large strain consolidation is established, which comprehensively accounts for vertical strain, soil self-weight, geometrical nonlinearity, continuity of pore water flow, the relative velocity of the fluid and solid phases, and changing compressibility and hydraulic conductivity during consolidation. Then the numerical solution is obtained with the finite difference method (FDM). Verification of the FDM solution shows excellent accuracy. On this basis, we investigate the influence of the non-Darcian flow on consolidation behavior. The results show that the increase of the non-Darcian exponent will accelerate the consolidation rate in the beginning, while slowing down the consolidation rate in the end. However, it has no effect on the final settlement of the soil layer. In addition, boundary drainage conditions have a huge impact on the consolidation rate, whether it is Darcian or non-Darcian flow.
\end{abstract}

\section{Introduction}

The deformation of the soil layer has always been one of the most important fields in geotechnical engineering and civil engineering, which is closely related to the theory of large strain consolidation. If the settlement of the soil layer is not predicted accurately, a large amount of manpower and material resources will be wasted, especially in terms of reclamation projects. Therefore, it is important to establish the theory of $1 \mathrm{D}$ large strain consolidation that can reflect the settlement of the soil layer more precisely.

So far, in the field of large strain consolidation, plenty of great progress has been made in terms of analytical theory, numerical simulations, experimental verifications, and other aspects [1-8]. Most of these methods, however, were based on the assumption that the water flow in the soils obeyed Darcy's law. In fact, Darcy's law was obtained from the indoor sand experiment in the 1850s, which was initially established for coarse-grained soils [9]. The inaccuracy of Darcy's law in fine-grained soils (e.g., soft clay and dredged fill) has been confirmed by many studies [10-15]. As fine-grained soils are widespread in the civil engineering, it is of theoretical and practical significance to study one-dimensional large strain consolidation based on non-Darcian flow.
Slepicka [16] presented a non-Darcian flow law as follows:

$$
v=k i^{m}
$$

in which $v$ signifies the seepage velocity, $k$ represents the vertical hydraulic conductivity, $i$ represents the hydraulic gradient, and $m$ is the non-Darcian flow exponent. Based on (1), many studies have incorporated this flow law into the theories of consolidation [17-21]. All studies above, however, accounted for small strain consolidation rather than large strain consolidation. Zhao et al. [22] first proposed a piecewise linear model, referred to as CNDF1, which has been proven to be both reliable and robust in the analysis of large strain consolidation with the non-Darcian flow.

In this paper, we aim to propose a numerical solution for 1D large strain consolidation with nonlinear flow law. The governing equation comprehensively accounts for the large strain, geometrical nonlinearity, self-weight of the soil, the relative velocity of the fluid and solid phases, nonlinear compression, and permeability relationship, and the numerical solution is verified with CNDF1 model. Although the method presented in this paper is totally different from that in the previous study [22], the results of the comparison are 


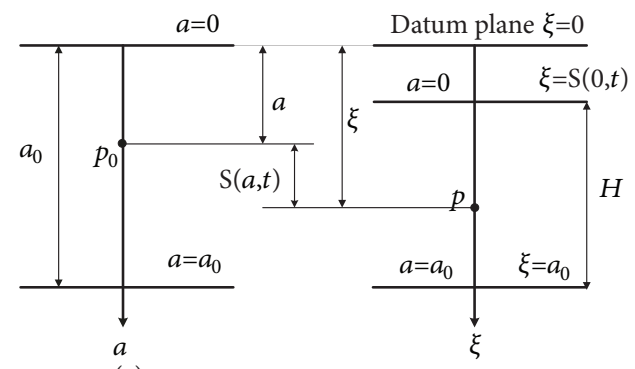

(a)

(b)

FIGURE 1: Lagrangian and convective coordinates: (a) initial configuration at $t=0$; (b) configuration at time $t$.

extremely close. Furthermore, the effects of the exponential flow on consolidation behavior are further analyzed.

\section{Mathematical Model}

2.1. Coordinate Systems. Figure 1 illustrates a saturated soil stratum of initial height $a_{0}$ with the bottom fixed and referenced to both the Lagrangian and the convective coordinate systems. The Lagrangian coordinate $a$ and the convective coordinate $\xi$ are both defined as positive downward.

The convective coordinate $\xi$ has its origin at the initial top surface of the stratum, which is referred to as the datum plane.

The Lagrangian coordinate $a$ and time $t$ are independent variables while the convective coordinate $\xi(a, t)$ is a variable depending on $a$ and $t$. The relationship between $a$ and $\xi$ is provided by Gibson [1]:

$$
\frac{\partial \xi}{\partial a}=\frac{1+e}{1+e_{o}}
$$

in which $e=e(a, t)$ represents the void ratio and $e_{0}$ represents the initial void ratio.

2.2. Basic Assumptions. We adopted the same basic assumptions in the theory of one-dimensional large strain consolidation $[1-5,7,8]$, except for water flow law:

(1) The soil layer is totally saturated and homogeneous.

(2) The pore water and soil particles are incompressible.

(3) The settlement of the soil layer is considered to be vertical only.

(4) The classical nonlinear constitutive relationships of effective stress, $\sigma^{\prime}$, and vertical hydraulic conductivity, $\mathrm{k}$, are adopted here:

$$
\begin{aligned}
& e-e_{1}=C_{c} \lg \left(\frac{\sigma_{1}^{\prime}}{\sigma^{\prime}}\right) \\
& e-e_{1}=C_{k} \lg \left(\frac{k}{k_{1}}\right)
\end{aligned}
$$

where $C_{c}$ is the compressibility index and $C_{k}$ is the permeability index, which are both constant. $\sigma_{1}{ }^{\prime}$ is a known effective stress and $k_{1}$ is a known hydraulic conductivity, which are user-specified and both constant.

(5) The external stress is applied on the layer instantaneously when $t=0$, which is assumed to be constant during the process of consolidation.
2.3. Governing Equation of Large Strain Consolidation with Non-Darcian Flow. Several basic equations for 1D large strain consolidation in the convective coordinate system are present here $[1,2]$ :

(1) Equation for vertical equilibrium of the soil mass:

$$
\frac{\partial \sigma}{\partial \xi}=\frac{G_{s}+e}{1+e} \gamma_{w}
$$

in which $\sigma$ is the total stress, $G_{s}$ is the specific gravity of the solid particles (constant), and $\gamma_{w}$ is the unit weight of water (constant).

(2) Equation for equilibrium of the pore water:

$$
\frac{\partial u}{\partial \xi}=\frac{\partial u_{e x}}{\partial \xi}+\gamma_{w}
$$

in which $u$ is the total pore pressure and $u_{e x}$ is the excess pore pressure.

(3) Principle of effective stress:

$$
\sigma=\sigma^{\prime}+u
$$

in which $\sigma^{\prime}$ is the vertical effective stress.

(4) Expression of the hydraulic gradient:

$$
i=\frac{1}{\gamma_{w}} \frac{\partial u_{e x}}{\partial \xi}
$$

(5) Equation for continuity of pore water flow:

$$
\frac{\partial}{\partial \xi}\left[\frac{e}{1+e}\left(v_{w}-v_{s}\right)\right]=-\frac{1}{1+e} \frac{\partial e}{\partial t}
$$

in which $v_{w}$ and $v_{s}$ are the velocities of the pore water and soil particle relative to datum plane.

When considering the relative motion of solid and liquid phases, the flow law as illustrated in (1) can be further described as follows:

$$
\frac{e}{1+e}\left(v_{w}-v_{s}\right)=-k i^{m}
$$

Therefore, the governing equation can be developed with the combination of all above relations:

$$
\frac{\partial e}{\partial t}=\left(1+e_{0}\right) \frac{\partial}{\partial a} k\left(\frac{G_{s}-1}{1+e}-\frac{d \sigma^{\prime}}{d e} \frac{\partial e}{\partial a} \frac{1+e_{0}}{1+e} \frac{1}{\gamma_{w}}\right)^{m}
$$

where $k$ and $\sigma^{\prime}$ both have relation to void ratio as illustrated in (3) and (4). 


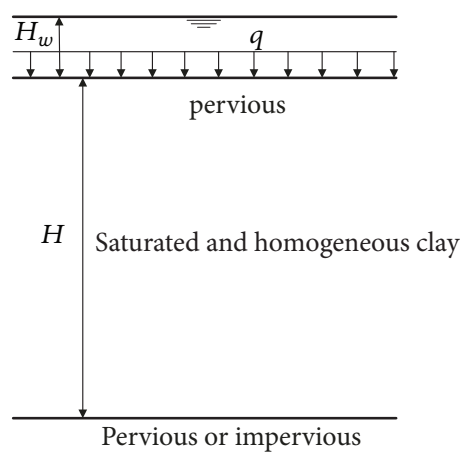

FIGURE 2: The consolidation problem studied.

2.4. Boundary Conditions. The saturated and homogeneous soil layer is taken to have an initially uniform density, and the initial void ratio can be considered as constant throughout the whole layer [23]:

$$
e(a, 0)=e_{o}
$$

Drainage conditions in the vertical direction are either pervious top and pervious bottom (PTPB) or pervious top and impervious bottom (PTIB), as illustrated in Figure 2.

The top boundary is generally pervious, where the excess pore pressure is zero. Therefore, the boundary condition should be as follows:

$$
\begin{aligned}
& e(0, t)=e_{1}+C_{c} \lg \left[\frac{\sigma_{1}^{\prime}}{\sigma^{\prime}(0, t)}\right] \\
& \sigma^{\prime}(0, t)=q+\sigma_{0}^{\prime}
\end{aligned}
$$

where $q$ is the instantaneous external stress applied on the surface of the soil stratum at the beginning of consolidation, which is assumed to be constant. $\sigma_{0}{ }^{\prime}$ is the initial effective stress:

$$
\sigma_{0}{ }^{\prime}=\sigma_{1}{ }^{\prime} \exp \left(\frac{e_{1}-e_{0}}{C_{c}}\right)
$$

Similarly, for the pervious bottom boundary, the boundary condition should be

$$
e\left(a_{0}, t\right)=e_{1}+C_{c} \lg \left(\frac{\sigma_{1}^{\prime}}{\sigma^{\prime}\left(a_{0}, t\right)}\right)
$$

Since the settlement of the fix bottom boundary is always zero, it can be assumed that the bottom boundary is always in the final state of consolidation [23]. Therefore,

$$
\sigma^{\prime}\left(a_{0}, t\right)=\sigma^{\prime}\left(a_{0}, \infty\right)=\left(\gamma_{s}-\gamma_{w}\right) \frac{a_{0}}{1+e_{0}}+q+\sigma_{0}^{\prime}
$$

where $\gamma_{s}=G_{s} \cdot \gamma_{w}$ is the unit weight of solid particles (constant).

The bottom boundary can also be impervious, where the hydraulic gradient is zero. Therefore, for the impervious bottom boundary, the boundary condition should be

$$
\left.\frac{\partial e}{\partial a}\right|_{a=a_{0}}=-\frac{\gamma_{s}-\gamma_{w}}{1+e_{0}} a_{v}
$$

where $a_{v}=-d e / d \sigma^{\prime}$ is the coefficient of compressibility.

\section{Derivation of Numerical Solution}

3.1. Alternative Form of the Governing Equation. For the convenience of following studies, an equivalent Darcy hydraulic conductivity, $K_{d}=k i^{m-1}$, is adopted in this paper. In this way, (1) can be expressed in a form similar to Darcy's law, namely, $v=K_{d} i$. The expression of $K_{d}$ is as follows:

$$
K_{d}=k\left(\frac{G_{s}-1}{1+e}-\frac{d \sigma^{\prime}}{d e} \frac{\partial e}{\partial a} \frac{1+e_{0}}{1+e} \frac{1}{\gamma_{w}}\right)^{m-1}
$$

Therefore, (11) can be further expressed as

$$
\begin{aligned}
\frac{\partial e}{\partial t}= & \left(G_{s}-1\right) \frac{d}{d e}\left[\frac{K_{d}\left(1+e_{0}\right)}{1+e}\right] \frac{\partial e}{\partial a} \\
& -\frac{\left(1+e_{0}\right)^{2}}{\gamma_{w}} \frac{\partial}{\partial a}\left[\frac{K_{d}}{1+e} \frac{d \sigma^{\prime}}{d e} \frac{\partial e}{\partial a}\right]
\end{aligned}
$$

or in the alternative form:

$$
\frac{\partial e}{\partial t}=A \frac{\partial e}{\partial a}+B\left(\frac{\partial e}{\partial a}\right)^{2}+C \frac{\partial^{2} e}{\partial a^{2}}
$$

where

$$
\begin{aligned}
& A=\left(G_{S}-1\right) \frac{\mathrm{d}}{\mathrm{d} e}\left[\frac{K_{d}\left(1+e_{0}\right)}{1+e}\right] \\
& B=-\frac{\left(1+e_{0}\right)^{2}}{\gamma_{w}}\left[\frac{\mathrm{d} \sigma^{\prime}}{\mathrm{d} e} \cdot \frac{d}{d e}\left(\frac{K_{d}}{1+e}\right)+\frac{K_{d}}{1+e} \frac{\mathrm{d}^{2} \sigma^{\prime}}{\mathrm{d} e^{2}}\right] \\
& C=-\frac{\left(1+e_{0}\right)^{2} K_{d}}{\gamma_{w}(1+e)} \frac{\mathrm{d}^{2} \sigma^{\prime}}{\mathrm{d} e^{2}}
\end{aligned}
$$

The derivation process of (21) is specifically illustrated in the appendix.

3.2. Discretization of the Governing Equation. As stated above, the finite difference method (FDM) is introduced to develop the numerical solution for (21). Firstly, the spatial domain $0 \leq a \leq a_{0}$ is subdivided into $M$ equal elements from the top down by the proportional spacing $\Delta a$. If the nodal point of spatial domain is denoted as $a_{i}$

$$
a_{i}=i \Delta a
$$


Meanwhile, if the nodal point of time is denoted as $t_{j}$,

$$
t_{j}=j \Delta t
$$

The Crank-Nicolson difference scheme is used in this paper for its relative stability. Therefore, the difference scheme of (21) can be obtained:

$$
\begin{aligned}
& \frac{e_{i}^{j}-e_{i}^{j-1}}{\Delta t} \\
& =\mathrm{A}_{i}^{j-1} \frac{e_{i+1}^{j-1}-e_{i-1}^{j-1}}{2 \Delta a}+B_{i}^{j-1}\left(\frac{e^{j-1}{ }_{i+1}-e_{i-1}^{j-1}}{2 \Delta a}\right)^{2} \\
& \quad+\frac{1}{2} C_{i}^{j-1} \\
& \quad \times\left(\frac{e_{i+1}^{j}+e_{i-1}^{j}-2 e_{i}^{j}}{\Delta a^{2}}+\frac{e_{i+1}^{j-1}+e_{i-1}^{j-1}-2 e_{i}^{j-1}}{\Delta a^{2}}\right), \\
& i=1,2, \ldots, M
\end{aligned}
$$

where $e_{i}^{j}$ denotes the void ratio at $a_{i}=i \Delta a$ and $t_{j}=j \Delta t$. $\mathrm{A}_{i}^{j-1}, B_{i}^{j-1}$, and $C_{i}^{j-1}$ are the corresponding value at $a_{i}=i \Delta a$ and $t_{j_{-1}}=(j-1) t$. For the sake of calculation, (27) can be rewritten in the alternative form as follows:

$$
\begin{aligned}
e_{i+1}^{j}- & 2\left(1+\frac{\Delta a^{2}}{\Delta t C_{i}^{j-1}}\right) e_{i}^{j}+e_{i-1}^{j} \\
= & -e_{i+1}^{j-1}+2\left(1-\frac{\Delta a^{2}}{\Delta t C_{i}^{j-1}}\right) e_{i}^{j-1}-e_{i-1}^{j-1} \\
& -\frac{A_{i}^{j-1}}{C_{i}^{j-1}} \Delta a\left(e_{i+1}^{j-1}-e_{i-1}^{j-1}\right) \\
& -\frac{B_{i}^{j-1}}{2 C_{i}^{j-1}}\left(e_{i+1}^{j-1}-e_{i-1}^{j-1}\right)^{2}, \quad i=1,2, \ldots, M
\end{aligned}
$$

The initial condition can be expressed in terms of discrete nodal points:

$$
e_{i}^{0}=e_{o}, \quad i=1,2, \ldots, M
$$

and the boundary conditions can also be expressed as

$$
\begin{aligned}
& \text { PTIB : }\left\{\begin{array}{l}
e_{0}^{j}=e_{1}+C_{c} \lg \left[\frac{\sigma_{1}^{\prime}}{q+\sigma_{1}{ }^{\prime} \exp \left(\left(e_{1}-e_{0}\right) / C_{c}\right)}\right] \\
e_{M+1}^{j}=e_{M-1}^{j}-\frac{2 \Delta a\left(\gamma_{s}-\gamma_{w}\right)}{1+e_{0}} a_{v}{ }^{j}
\end{array}\right. \\
& \text { PTPB : }\left\{\begin{array}{l}
e_{0}^{j}=e_{1}+C_{c} \lg \left[\frac{\sigma_{1}^{\prime}}{q+\sigma_{1}{ }^{\prime} \exp \left(\left(e_{1}-e_{0}\right) / C_{c}\right)}\right] \\
e_{M+1}^{j}=e_{1}+C_{c} \lg \left[\frac{\sigma_{1}{ }_{1}}{\left(\gamma_{s}-\gamma_{w}\right)\left(a_{0} /\left(1+e_{0}\right)\right)+q+\sigma_{1}{ }^{\prime} \exp \left(\left(e_{1}-e_{0}\right) / C_{c}\right)}\right]
\end{array}\right.
\end{aligned}
$$

where $e_{0}^{j}$ denotes the void ratio at the top boundary and $e_{M+1}^{j}$ denotes the void ratio at the bottom boundary.

For PTIB, by substituting (30) into (28), equation (28) can be expressed in terms of matrix, namely, $[D]\{e\}=[E]$ :

$$
\left[\begin{array}{cccccc}
D_{1} & 1 & & & & \\
1 & D_{2} & 1 & & & \\
& 1 & D_{3} & 1 & & \\
& & \ddots & \ddots & \ddots & \\
& & & 1 & D_{M-1} & 1 \\
& & & & 2 & D_{M}
\end{array}\right]^{j-1}\left\{\begin{array}{c}
e_{1} \\
e_{2} \\
e_{3} \\
\vdots \\
e_{M-1} \\
e_{M}
\end{array}\right\}^{j}
$$

$$
=\left\{\begin{array}{c}
E_{1} \\
E_{2} \\
E_{3} \\
\vdots \\
E_{M-1} \\
E_{M}
\end{array}\right\}
$$

where

$$
\begin{aligned}
& D_{i}=-2\left(1+\frac{\Delta a^{2}}{\Delta t C_{i}^{j-1}}\right) \\
& E_{1}=-2 e_{0}^{j-1}+2\left(1-\frac{\Delta a^{2}}{\Delta t C_{1}^{j-1}}\right) e_{1}^{j-1}-e_{2}^{j-1}
\end{aligned}
$$




$$
\begin{aligned}
& -\frac{\Delta a A_{1}^{j-1}}{C_{1}^{j-1}}\left(e_{2}^{j-1}-e_{0}^{j-1}\right) \\
& -\frac{B_{1}^{j-1}}{2 C_{1}^{j-1}}\left(e_{2}^{j-1}-e_{0}^{j-1}\right)^{2} \\
E_{\mathrm{i}}= & -e_{i+1}^{j-1}+2\left(1-\frac{\Delta a^{2}}{\Delta t C_{i}^{j-1}}\right) e_{i}^{j-1}-e_{i-1}^{j-1} \\
& -\frac{\Delta a A_{i}^{j-1}}{C_{i}^{j-1}}\left(e_{i+1}^{j-1}-e_{i-1}^{j-1}\right) \\
& -\frac{B_{i}^{j-1}}{2 C_{i}^{j-1}}\left(e_{i+1}^{j-1}-e_{i-1}^{j-1}\right)^{2} \\
E_{M}= & 2\left(1-\frac{\Delta a^{2}}{\Delta t C_{M}^{j-1}}\right) e_{M}^{j-1}-2 e_{M-1}^{j-1}-\frac{2 \Delta a A_{M}^{j-1}}{C_{M}^{j-1}} \Gamma_{M}^{j-1} \\
& -\frac{2 \Delta a^{2} B_{M}^{j-1}}{C_{M}^{j-1}}\left(\Gamma_{M}^{j-1}\right)^{2}+4 \Delta a \Gamma_{M}^{j-1}
\end{aligned}
$$

where

$$
\Gamma_{M}=\left.\frac{\partial e}{\partial a}\right|_{a=a_{0}}=-\frac{\gamma_{s}-\gamma_{w}}{\left(1+e_{0}\right)} a_{v}
$$

Similarly, for PTPB, (28) can be expressed as follows:

$$
\begin{aligned}
& {\left[\begin{array}{cccccc}
D_{1} & 1 & & & & \\
1 & D_{2} & 1 & & & \\
& 1 & D_{3} & 1 & & \\
& & \ddots & \ddots & \ddots & \\
& & 1 & D_{M-1} & 1 \\
& \\
& \\
& \\
& \\
E_{3} \\
E_{M-1} \\
F
\end{array}\right\}}
\end{aligned}
$$

where

$$
\begin{aligned}
F= & -e_{M-1}^{j-1}+2\left(1-\frac{\Delta a^{2}}{\Delta t C_{M}^{j-1}}\right) e_{M}^{j-1}-2 e_{M+1}^{j-1} \\
& -\frac{\Delta a A_{M}^{j-1}}{C_{M}^{j-1}}\left(e_{M+1}^{j-1}-e_{M-1}^{j-1}\right) \\
& -\frac{B_{M}^{j-1}}{2 C_{M}^{j-1}}\left(e_{M+1}^{j-1}-e_{M-1}^{j-1}\right)^{2}
\end{aligned}
$$

and the other symbols are the same as those in (32).

It can be seen that coefficient matrices $[D]$ are known when $t=(j-1) \Delta t$, which are both symmetrical threediagonal. Therefore, the value of $e_{i}^{j}$ at any moment $t_{j}=j \Delta t$ can be obtained once we know the value of the void ratio at the previous moment $t_{j-1}=(j-1) \Delta t$. With Matlab programming, it is easy to obtain the distribution of the void ratio during the process of consolidation, as illustrated in Figure 3.

3.3. Excess Pore Pressure, Discharge Velocity, Settlement, and Average Degree of Consolidation. Once the value of $e_{i}^{j}$ is obtained, the value of excess pore stress can also be determined according to (6) and (7):

$$
u_{e x, i}^{j}=\left(\gamma_{s}-\gamma_{w}\right) \frac{a_{i}^{j}}{1+e_{0}}+q+\sigma_{0}-\sigma_{i}^{\prime j}
$$

where the effective stress $\sigma_{i}^{\prime j}$ can be calculated from (3):

$$
\sigma_{i}^{\prime j}=\sigma_{1}^{\prime} \exp \left(\frac{e_{1}-e_{i}^{j}}{C_{c}}\right)
$$

Similarly, $k_{i}{ }^{j}$ can be calculated from (4):

$$
k_{i}^{j}=k_{1} \exp \left(\frac{e_{i}^{j}-e_{1}}{C_{k}}\right)
$$

Therefore, the velocity of water flow in the soil layer can be obtained according to (10):

$$
\begin{array}{r}
v_{i}^{j}=k_{i}^{j}\left(\frac{G_{s}-1}{1+e_{i}^{j}}-\frac{d \sigma^{\prime}}{d e} \frac{e^{j-1}{ }_{i+1}-e_{i-1}^{j-1}}{2 \Delta a} \frac{1+e_{0}}{1+e} \frac{1}{\gamma_{w}}\right)^{m} \\
i=1,2, \ldots, M
\end{array}
$$

According to (2), the settlement of the layer can be obtained:

$$
S_{t}=a_{0}-H=a_{0}-\frac{1}{1+e_{0}}\left(a_{0}+\sum_{i=1}^{M+1} \frac{e_{i}^{j}+e_{i-1}^{j}}{2} \Delta a\right)
$$

and the average degree of consolidation, $U_{a v g}$, is as follows:

$$
U_{\text {avg }}=\frac{S_{t}}{S_{\infty}}
$$




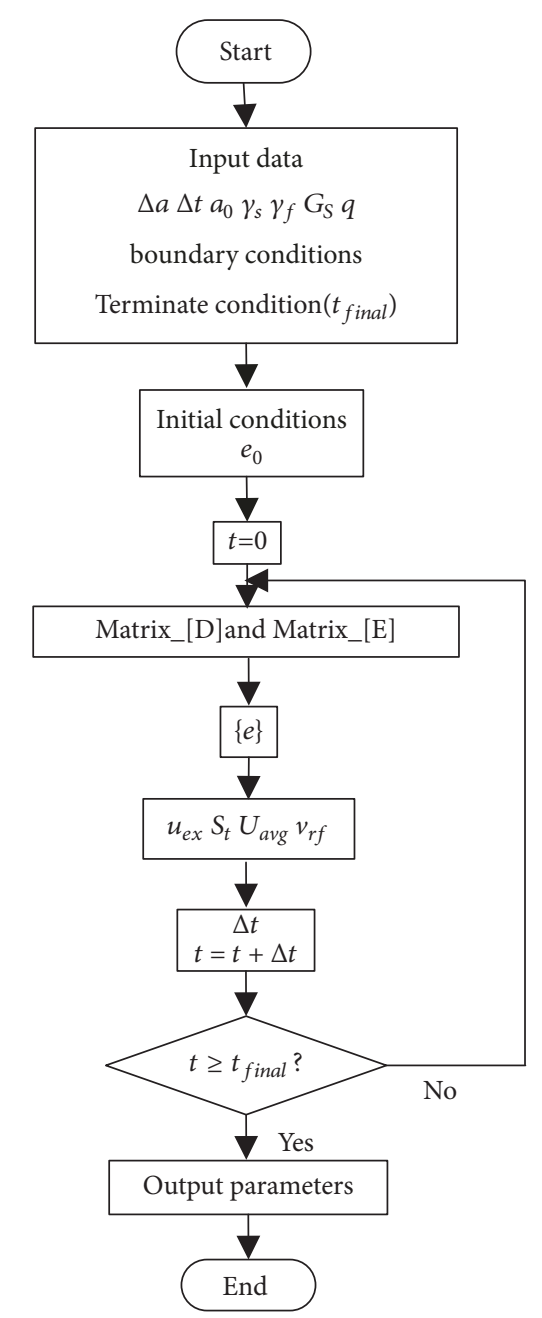

FIGURE 3: Flow chart for computer procedure.

where $S_{\infty}$ is the ultimate settlement:

$$
S_{\infty}=a_{0}-\frac{1}{1+e_{0}}\left(a_{0}+\sum_{i=1}^{M+1} \frac{e_{i}^{\infty}+e_{i-1}^{\infty}}{2} \Delta a\right)
$$

\section{Verification of Numerical Solutions}

The following example is to verify the accuracy of numerical method with CNDF1 model. A soil layer in [24] is investigated with $a_{0}=10 \mathrm{~m}$ and $G_{s}=2.78$. The initial void ratio, $e_{0}=1.571$, is constant throughout the whole stratum, and an instantaneous loading $q=100 \mathrm{kPa}$ is applied on the top surface of the stratum when $t=0$. Constitutive relationships are taken from the experimental data [24], $e_{1}=1.57, \sigma^{\prime}{ }_{1}=50 \mathrm{kPa}, k_{1}=1 \times 10^{-8}$, $C_{c}=0.6378$, and $C_{k}=0.8$. Taking the non-Darcian exponent $m=1.2$ for an example, the comparison results of FDM solutions and CNDF1 simulations are as follows.

Figure 4 illustrates the distribution of void ratio at several different moments, with Figure 4(a) for PTIB and Figure 4(b) for PTPB. In the figure, the dimensionless elevation, $\left(a_{0}-\right.$ $\xi) / H$, is adopted to describe the relative position of each element in the layer. Figure 5 shows the $u_{\text {ex }}$ profiles at several different moments obtained by two methods, with Figure 5(a) for PTIB and Figure 5(b) for PTPB. Figures 6 and 7 show the curves of settlement and the average degree of consolidation, respectively. Figure 8 shows the curves of discharge velocity at pervious boundaries; the signal of negative means that the direction of velocity is against with gravity.

The results of the comparison show excellent agreement between two methods. It means that FDM solution has good accuracy in the analysis of consolidation behavior with nonDarcian flow.

\section{Influence of Boundary Conditions}

According to Figures 4 and 5, the results indicate that the pervious bottom boundary (PTPB) results in smaller values of the void ratio and residual excess pore pressure at the same depth. The reason for this phenomenon is that a greater deformation has occurred. This means that pervious boundary can speed up the process of consolidation. Therefore, the consolidation rate under the double-drained condition is obviously faster than that under the single-drained condition, just as illustrated in Figures 6, 7, and 8. 


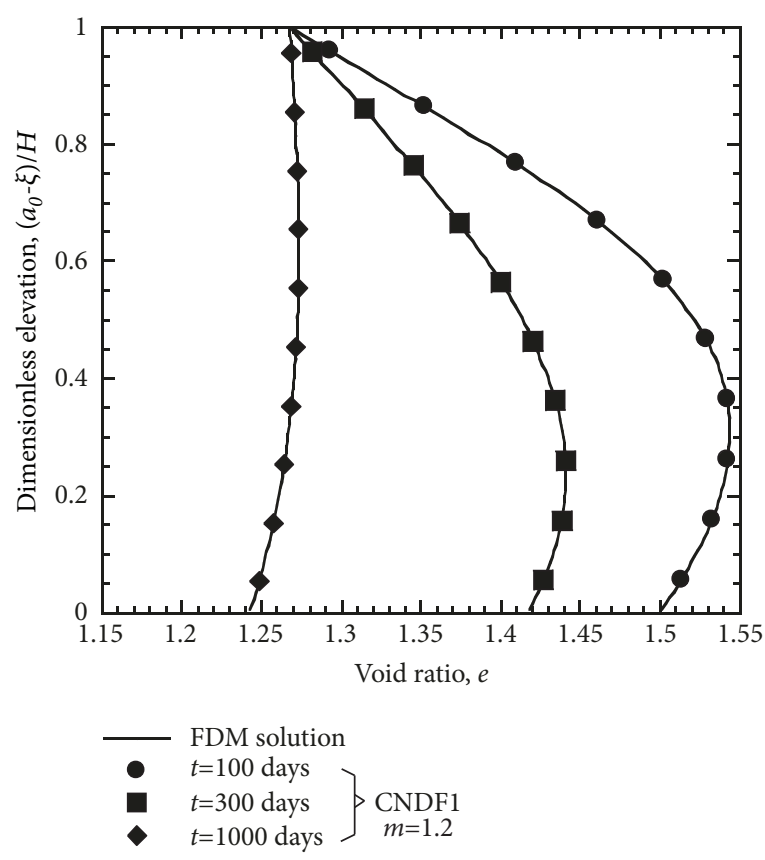

(a)

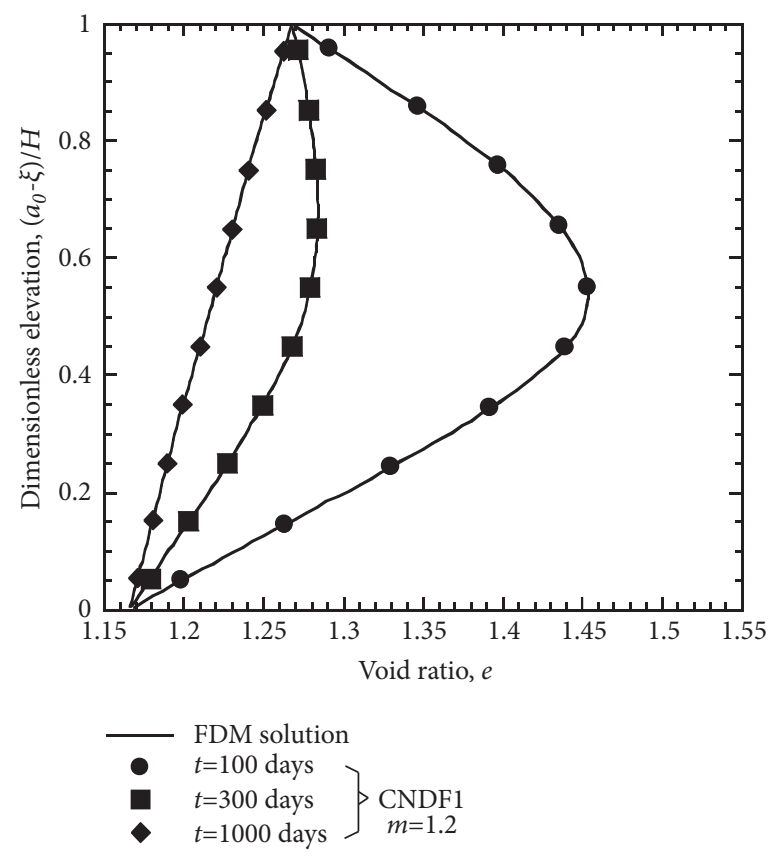

(b)

FIgURE 4: Verification for the void ratio: (a) PTIB; (b) PTPB.

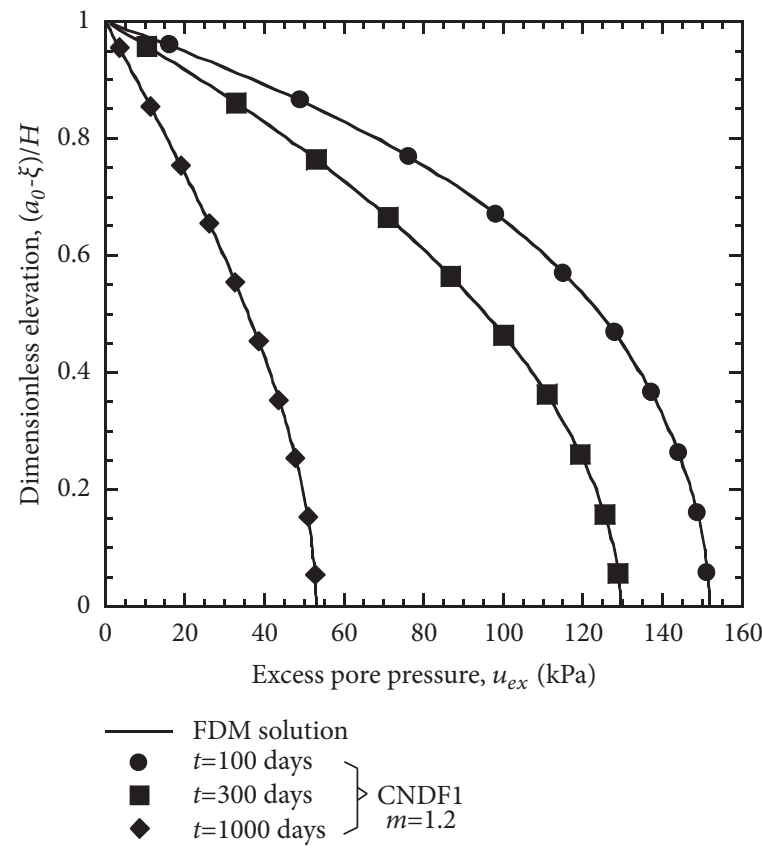

(a)

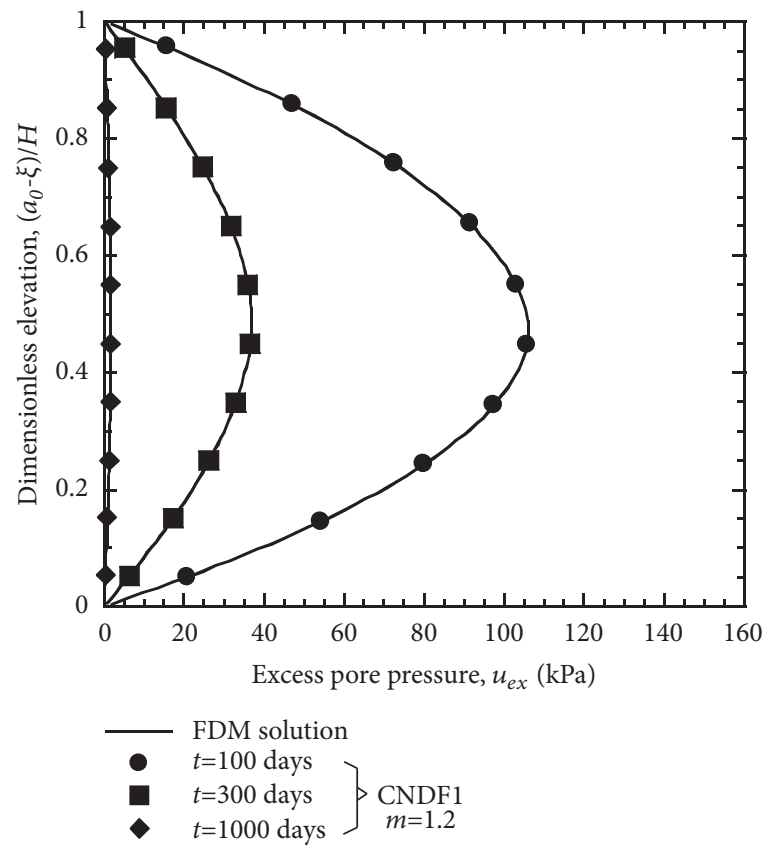

(b)

Figure 5: Verification for the excess pore pressure: (a) PTIB; (b) PTPB.

In addition, it is interesting that the value of void ratio at the pervious boundary is constant, while the value at the impervious bottom boundary is changed with time as shown in Figure 4(a). The reason can be easily illustrated by (18).

\section{Influence of Non-Darcian Flow on the Consolidation Behavior}

A soil layer with initial height of $8 \mathrm{~m}$ is affected by the external loading $q=100 \mathrm{kPa}$ when $t=0$. The initial void ratio is 1.445 


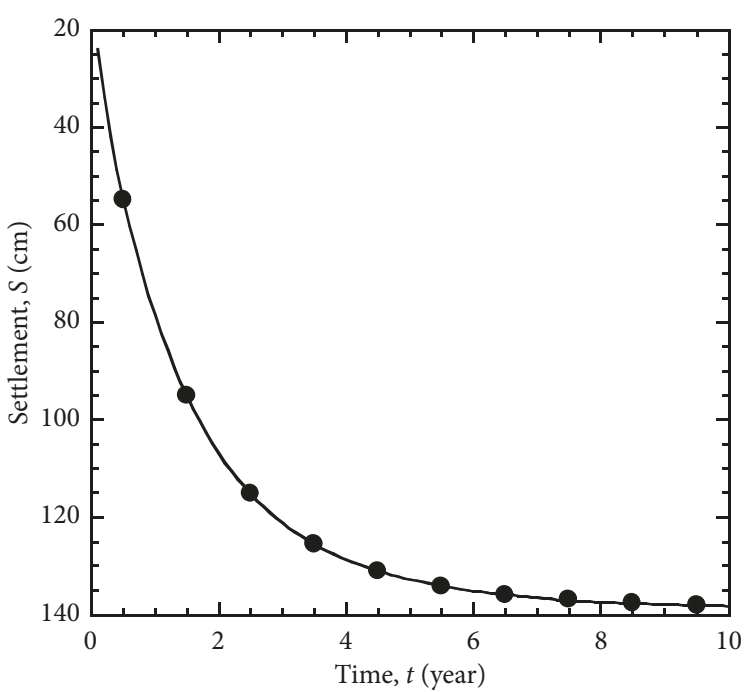

$m=1.2$

FDM solution

- CNDF1

(a)

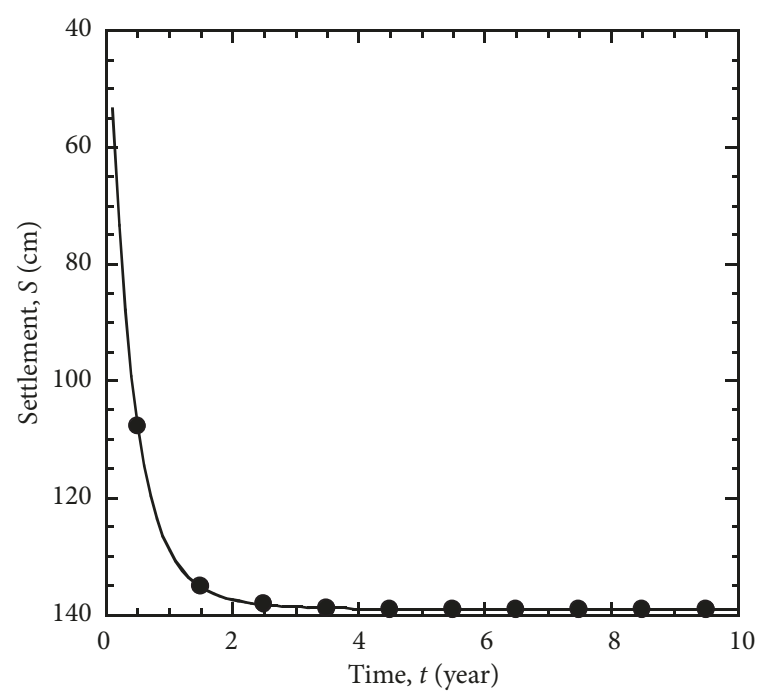

$m=1.2$

FDM solution

- CNDF1

Figure 6: Verification for the settlement of layer: (a) PTIB; (b) PTPB.

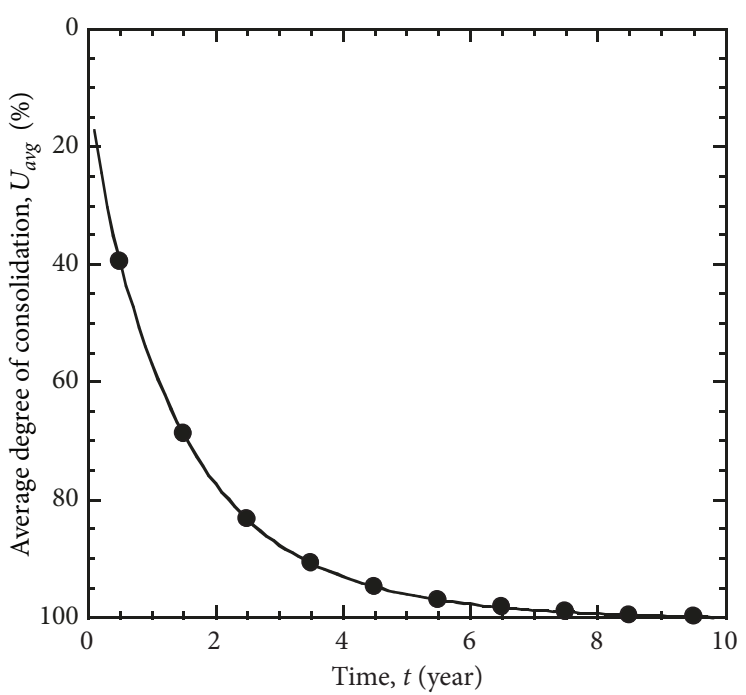

$m=1.2$

FDM solution

- CNDF1

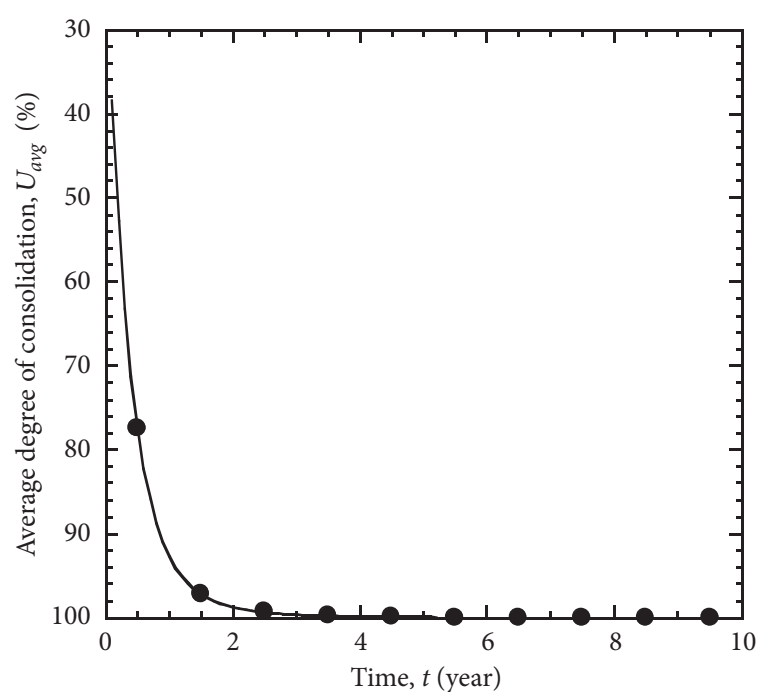

$m=1.2$

FDM solution

- CNDF1

(a)

(b)

FIGURE 7: Verification for the average degree of consolidation: (a) PTIB; (b) PTPB.

throughout the layer and the specific gravity is 2.61 . The constitutive relationships are taken from [25], where $e_{1}=1.57$, $\sigma_{1}^{\prime}=50 \mathrm{kPa}, k_{1}=1 \times 10^{-8}, C_{c}=0.6378$, and $C_{k}=0.8$. The effects of non-Darcian flow are investigated with $m$ increasing from 0.75 to 1.5 .

Figure 9 shows the curves of settlement, with Figure 9(a) for PTIB and Figure 9(b) for PTPB. There is an interesting phenomenon that the increase of the non-Darcian exponent will accelerate the consolidation rate in the beginning, while slowing down the consolidation rate in the end. The reason for this phenomenon is that the value of hydraulic gradient will decrease during the process of consolidation, and the discharge velocity will decrease with increasing the value of $m$ when the hydraulic gradient is less than 1 . It is noted that the consolidation rate under the double-drained condition is obviously faster than that under the single-drained condition, 


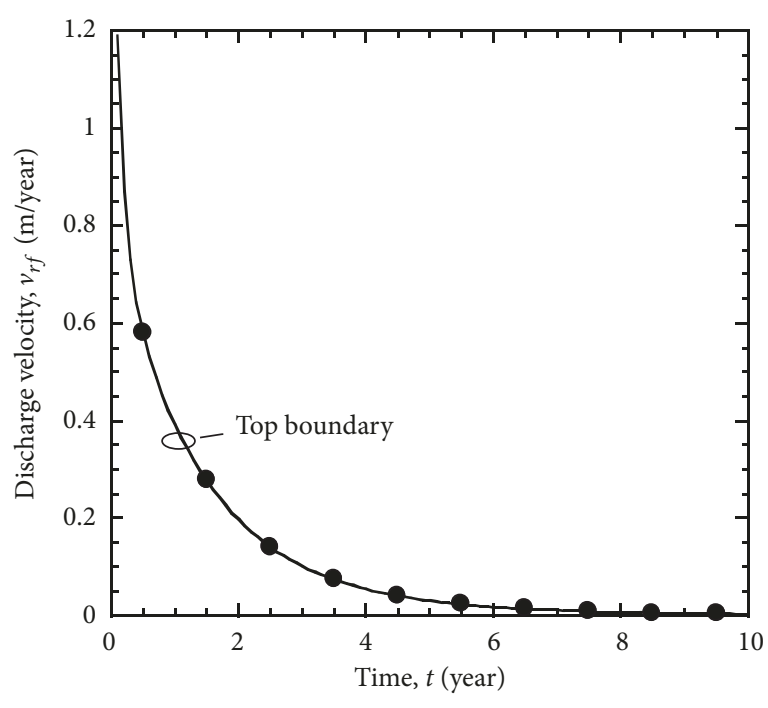

$m=1.2$

FDM solution

- CNDF1

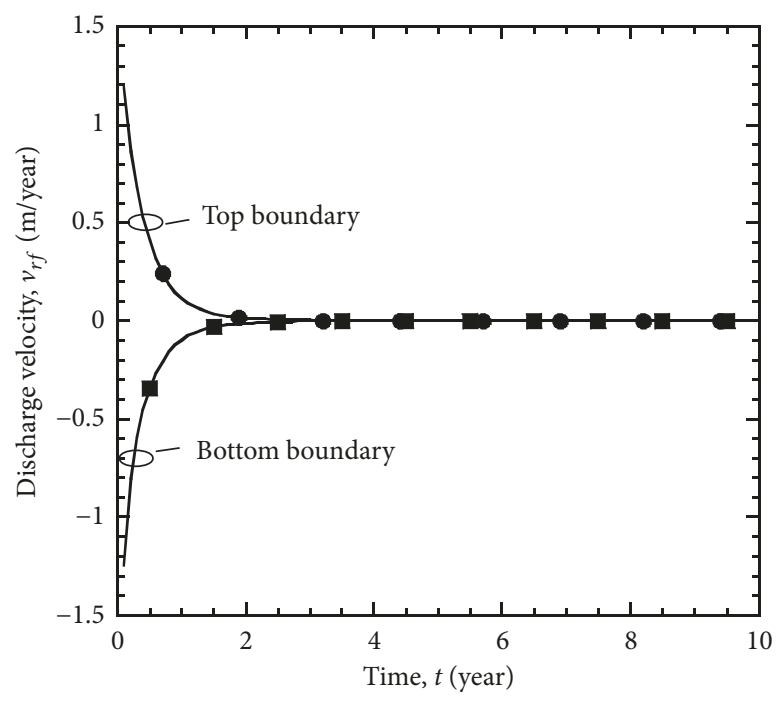

$m=1.2$

FDM solution

- $\left.\begin{array}{l}\text { Top boundary } \\ \text { - Bottom boundary }\end{array}\right\}$ CNDF1

(b)

FIGURE 8: Verification for the discharge velocity at the boundaries: (a) PTIB; (b) PTPB.

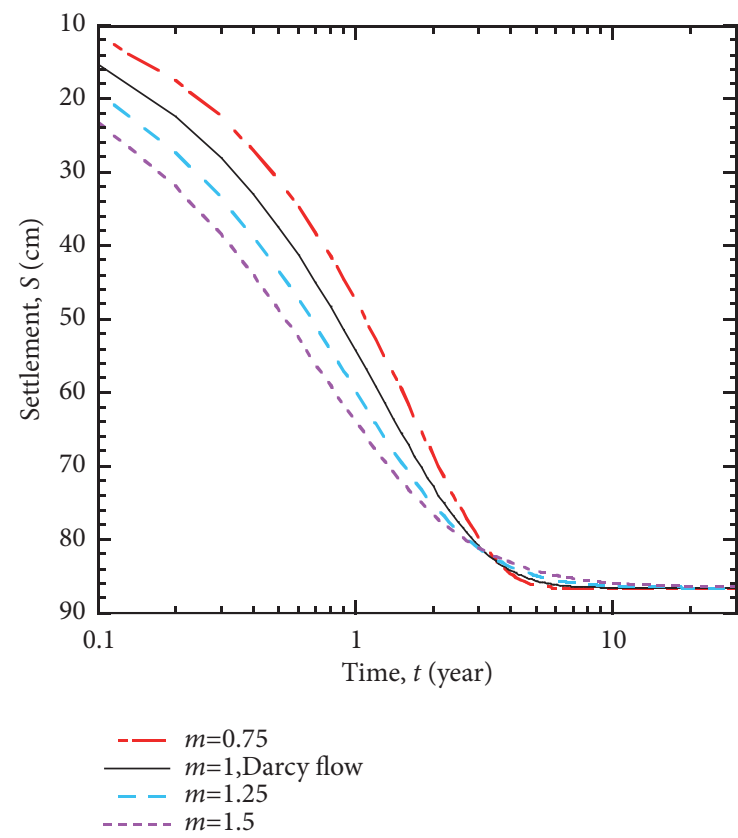

(a)

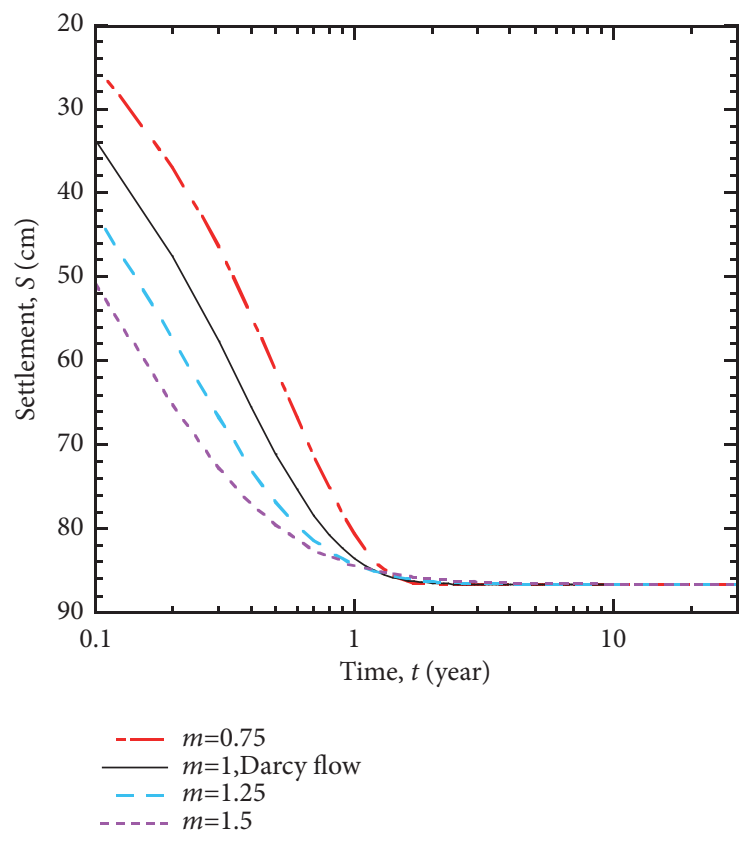

(b)

FIGURE 9: The settlement of layer with different value of $m$ : (a) PTIB; (b) PTPB.

but the ultimate settlement is the same in both cases, indicating that the drainage conditions at the bottom boundary have no effect on the final settlement.

Figures 10 and 11 show the distribution of void ratio and excess pore pressure for PTIB, respectively. In Figures 10(a) and 11(a), a larger value of $m$ results in smaller values of the void ratio residual excess pore pressure at the same depth. The reason for this phenomenon is that a greater deformation has occurred at this time ( $t=1$ year). This means that the increase of the value of $m$ can speed up the process of consolidation in the beginning. However, Figures 10(b) and 11(b) show an opposite trend. The reason for this phenomenon is that at the 


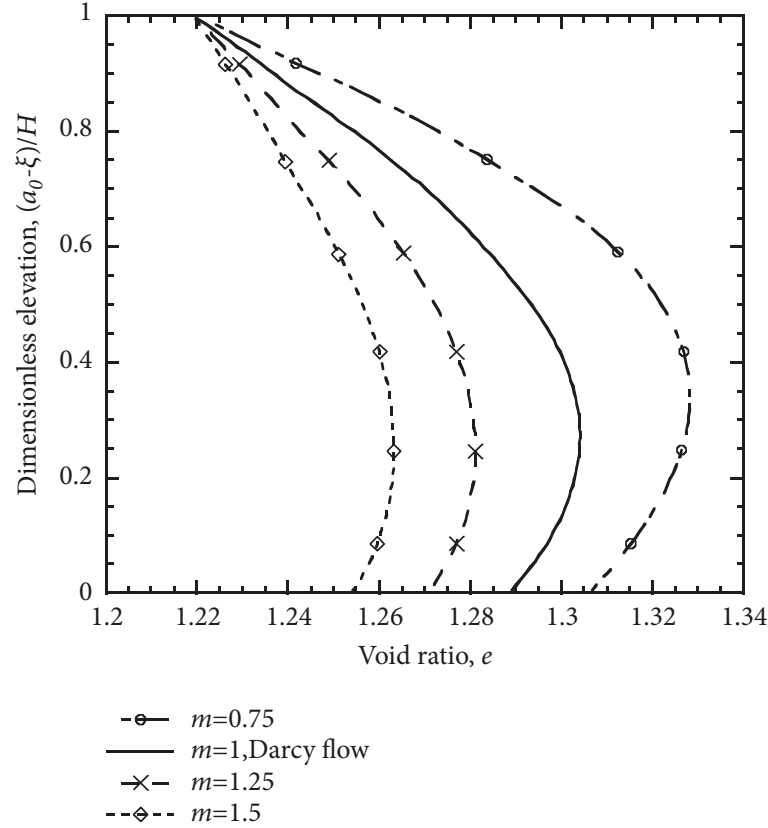

(a)

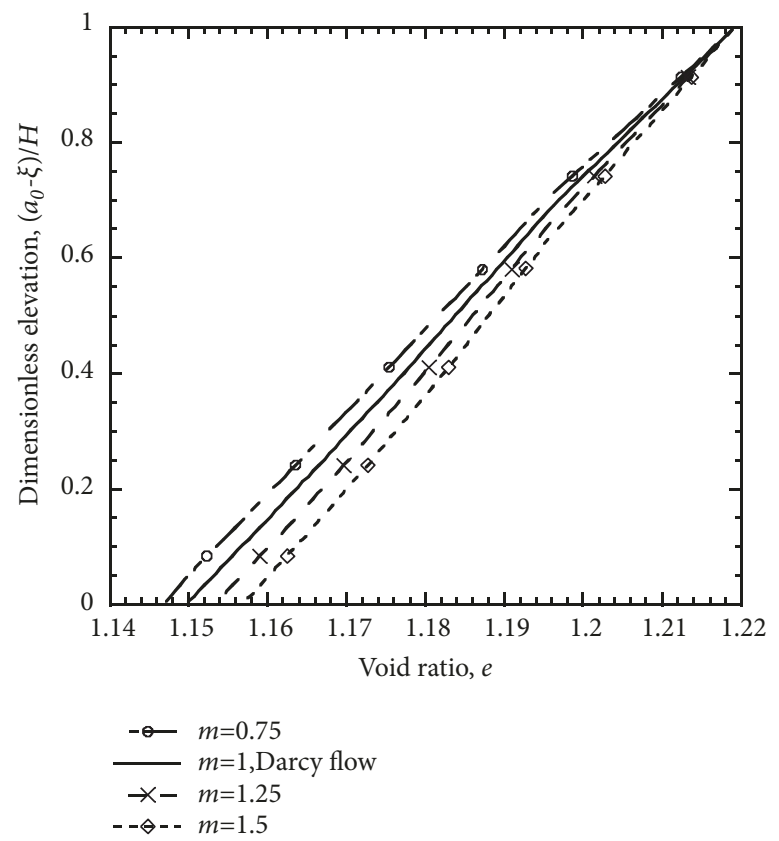

(b)

FIgURE 10: The distribution of void ratio for PTIB with different value of $m$ : (a) $t=1$ year; (b) $t=5$ years.

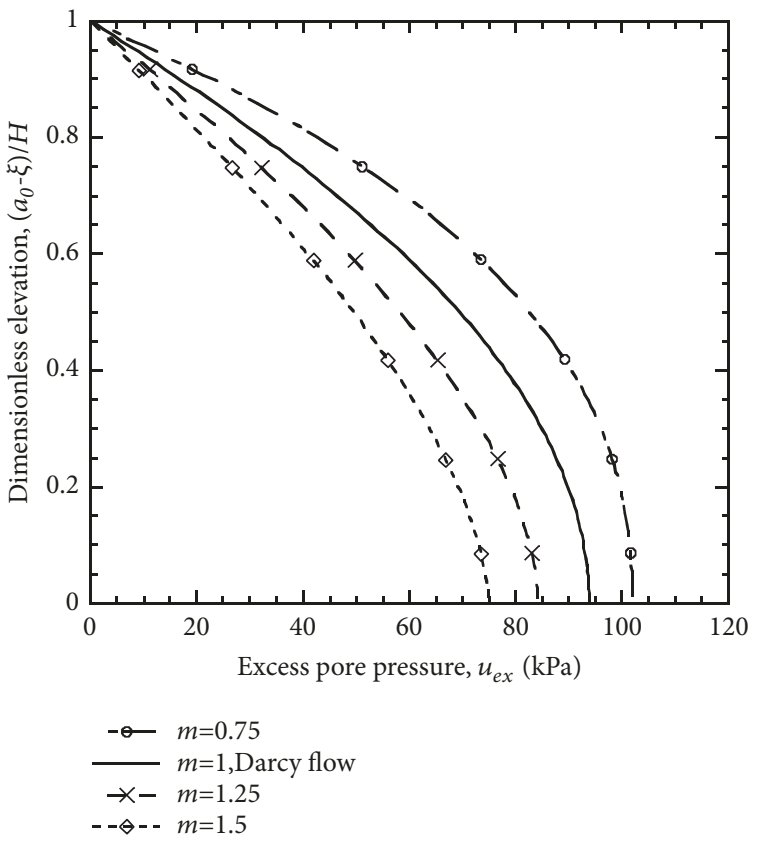

(a)

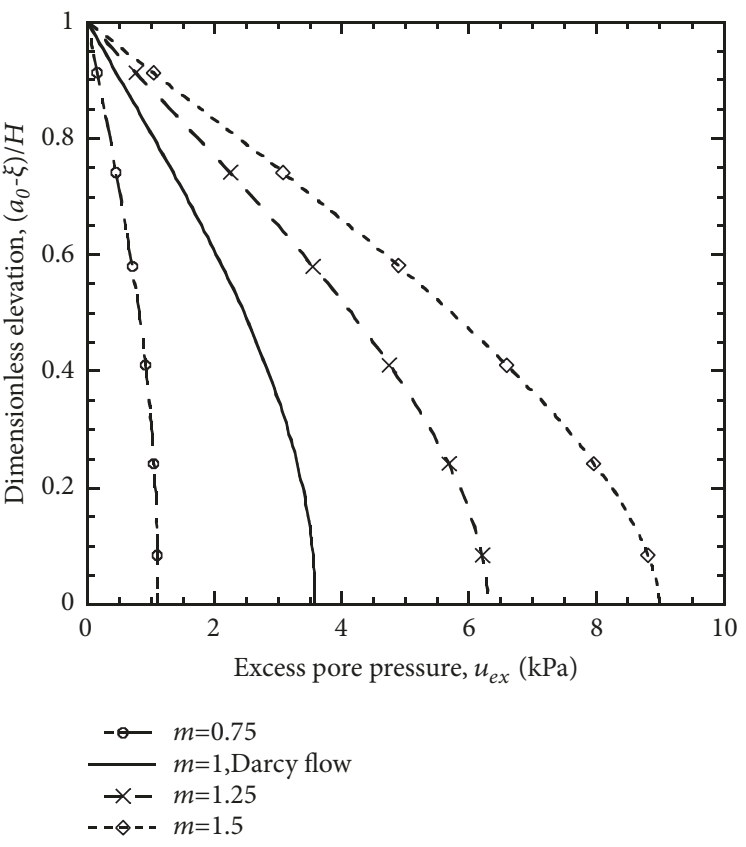

(b)

FIGURE 11: The distribution of excess pore pressure for PTIB with different value of $m$ : (a) $t=1$ year; (b) $t=5$ years.

later stage, the increase of the value of $m$ will slow down the consolidation rate in the end, as illustrated in the previous study [22].

Figure 12 illustrates the distribution of void ratio for PTPB. It can be observed that the non-Darcian flow $m$ also has a similar effect for PTPB. This means that for both PTIB and PTPB, a larger value of $m$ results in smaller values of the void ratio and residual excess pore pressure at the same depth in the beginning of consolidation and larger values of these parameters in the end. Besides, it is noted that the void ratio at the boundaries of stratum is constant during the process of consolidation. The reason is that the void ratio is only related to the external load and the soil self-weight, as illustrated in (17). Figure 13 illustrates the $u_{e x}$ profiles for PTPB. It can be seen that the value of $u_{e x}$ at the permeable boundaries is always zero, just as mentioned before. 


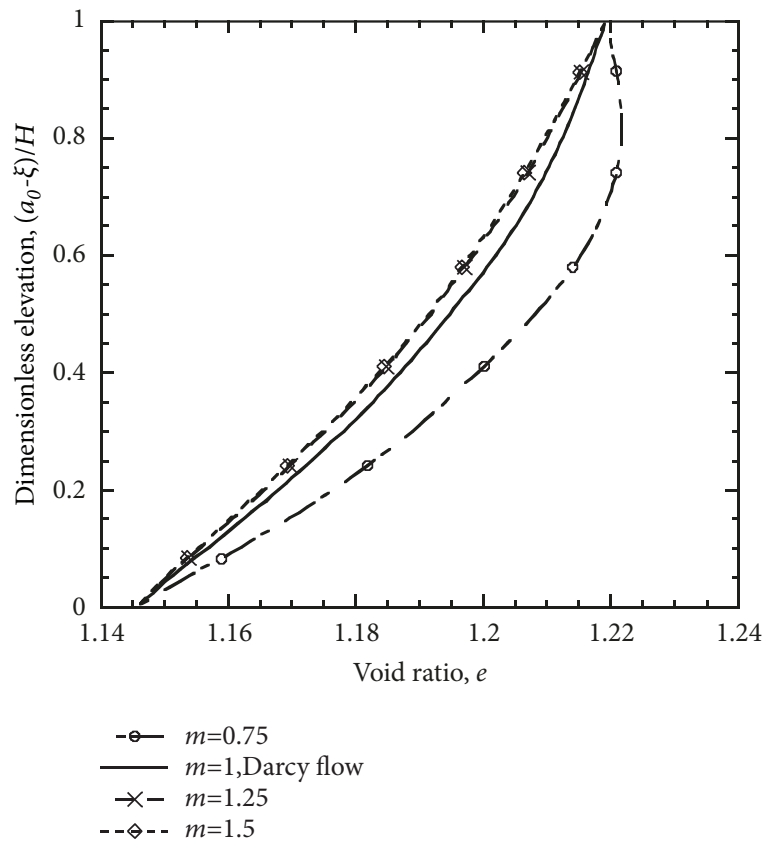

(a)

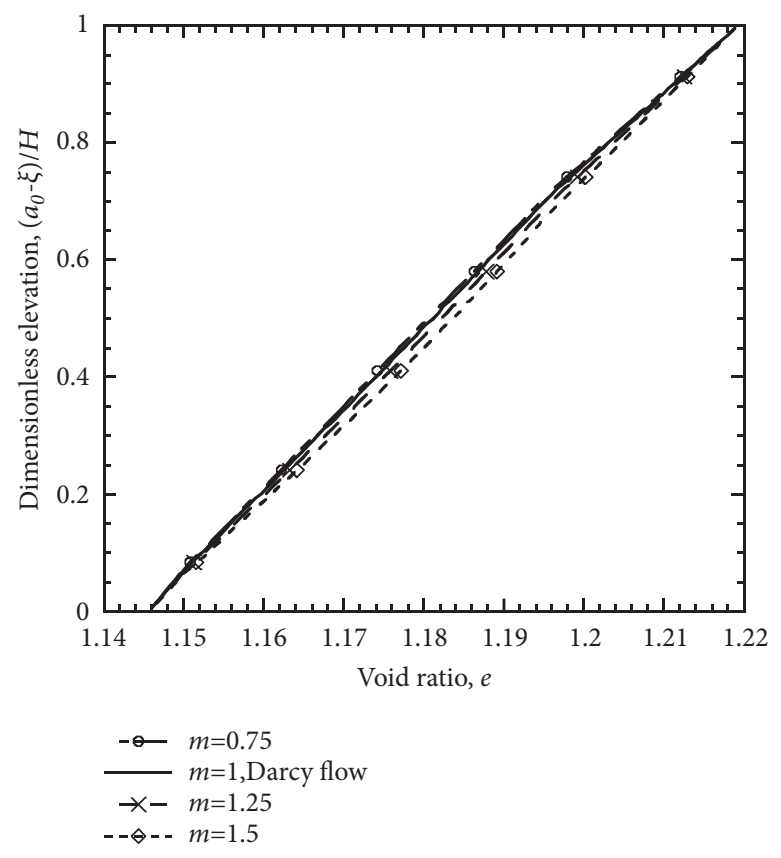

(b)

FIGURE 12: The distribution of void ratio for PTPB with different value of $m$ : (a) $t=1$ year; (b) $t=2$ years.

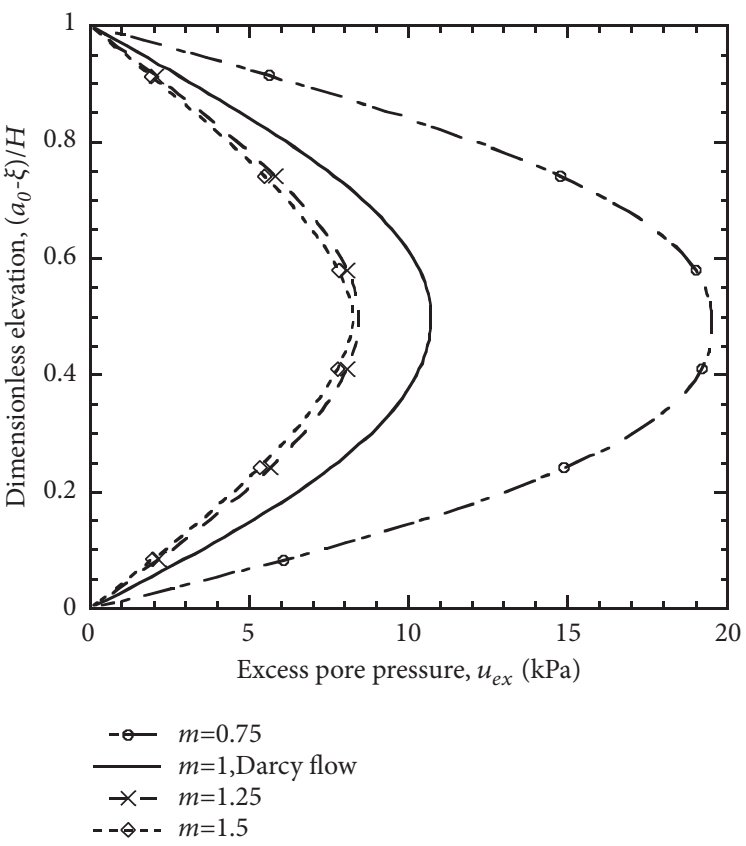

(a)

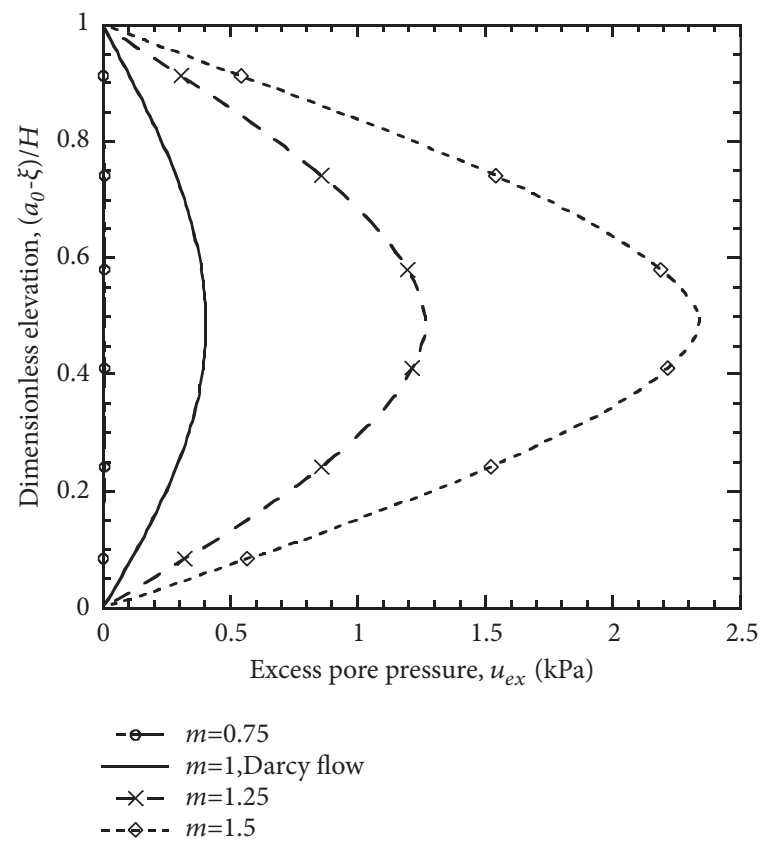

(b)

Figure 13: The distribution of excess pore pressure for PTPB with different value of $m$ :(a) $t=1$ year; (b) $t=2$ years.

\section{Influence of Soil Self-Weight on the Non- Darcian Consolidation}

The third example is to study the influence of soil self-weight on the non-Darcian consolidation. Figures 14 and 15 illustrate the settlement and $U_{\text {avg }}$ of the layer, respectively. It can be seen that the results of the final settlement are smaller than actual if soil self-weight is negligible, and there is also a significant difference in the results of the consolidation rate. When the soil self-weight is not considered, the consolidation rate is slower than the actual. However, this phenomenon is different from that in [26]. The reason is that in this paper, 


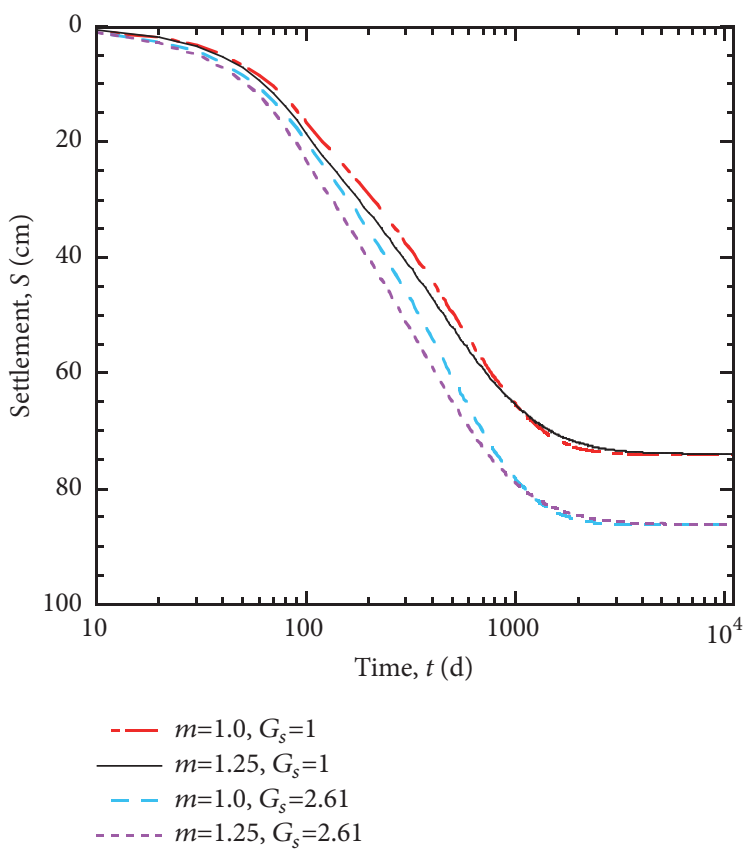

(a)

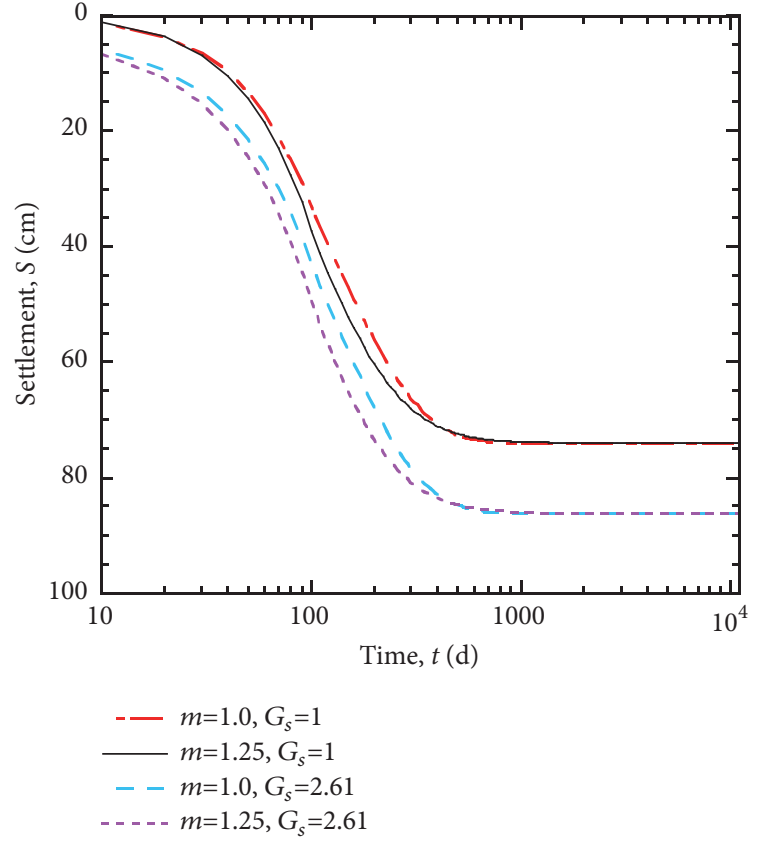

(b)

FIgURE 14: Effects of soil self-weight on the settlement: (a) PTIB;(b) PTPB.

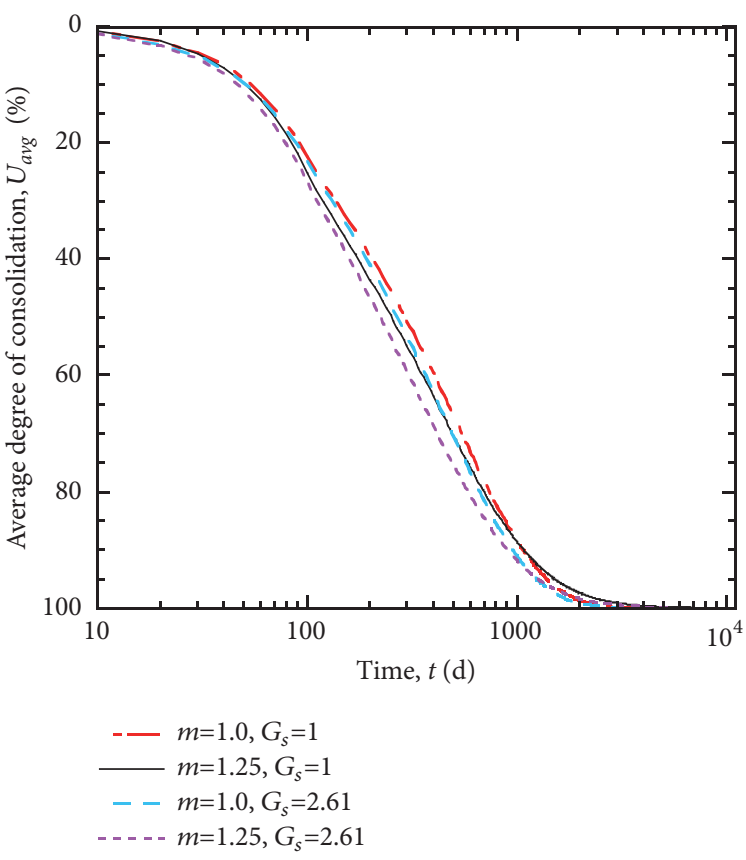

(a)

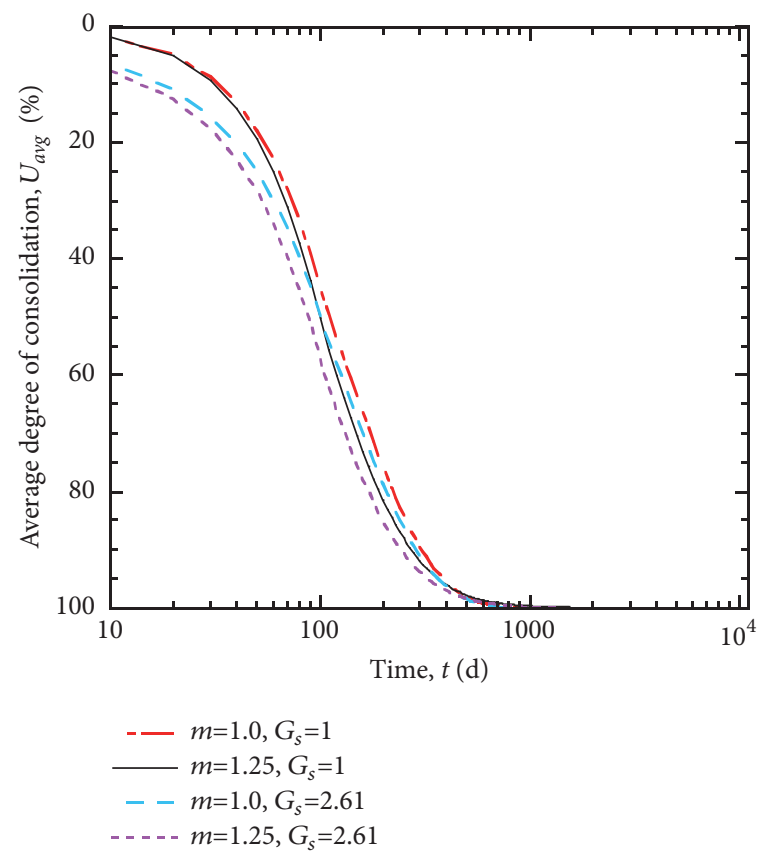

(b)

FIGURE 15: Effects of soil self-weight on the average degree of consolidation: (a) PTIB;(b) PTPB.

we adopt the same initial condition as [23], which is not mentioned in [26]. This means that the initial void ratio is constant throughout the whole layer, but the excess pore pressure is not zero under the initial condition, which results in a totally different conclusion of the effect of soil self-weight on the consolidation behavior.

\section{Conclusions}

In this paper, the governing equation of $1 \mathrm{D}$ large strain consolidation is first established, with the consideration of non-Darcian flow and geometrical nonlinearity. With finite difference method, numerical solution is obtained. 
Comparisons of FDM solution and CNDF1 simulation show excellent agreement. The influence of the nonlinear flow law on consolidation behavior is investigated.

(1) The FDM solution is in high accuracy, even though the complicated coefficient matrices $[D]$ take a large amount of time to calculate in the computer procedure. Besides, it is difficult to obtain the analytical solution of the governing equation. Therefore, we can adopt the FDM solution instead of the analytical solution to some extent.

(2) The increase of the non-Darcian exponent will accelerate the consolidation rate in the beginning, while slowing down the consolidation rate in the end.

(3) Although non-Darcian seepage will affect the consolidation rate, it has no effect on the final settlement of the soil layer.

(4) Boundary drainage conditions have a huge impact on the consolidation rate, whether it is Darcian or nonDarcian flow. The consolidation rate under the doubledrained condition is obviously faster than that under the single-drained condition.

(5) The influence of soil self-weight is significant. However, the different initial condition may result in a totally different conclusion of effect of soil self-condition on the consolidation behavior.

\section{Appendix}

\section{The Derivation Process of (21)}

Set $A=-\left(\gamma_{s}-\gamma_{f}\right)(\mathrm{d} / \mathrm{d} e)\left(K_{d}\left(1+e_{0}\right) / \gamma_{w}(1+e)\right)$, and $A_{1}=$ $K_{d}\left(1+e_{0}\right)^{2} / \gamma_{f}(1+e)$. Therefore, (20) can be expressed as follows:

$$
\frac{\partial e}{\partial t}=A \frac{\partial e}{\partial a}-\frac{\partial}{\partial a}\left(A_{1} \frac{\mathrm{d} \sigma^{\prime}}{\mathrm{d} e} \frac{\partial e}{\partial a}\right)
$$

where

$$
\begin{aligned}
\frac{\partial}{\partial a}\left[A_{1} \frac{\mathrm{d} \sigma^{\prime}}{\mathrm{d} e} \frac{\partial e}{\partial a}\right]= & \left(\frac{\partial A_{1}}{\partial e} \frac{\mathrm{d} \sigma^{\prime}}{\mathrm{d} e}+A_{1} \frac{\mathrm{d}^{2} \sigma^{\prime}}{\mathrm{d} e^{2}}\right)\left(\frac{\partial e}{\partial a}\right)^{2} \\
& +A_{1} \frac{\mathrm{d} \sigma^{\prime}}{\mathrm{d} e} \frac{\partial^{2} e}{\partial a^{2}}
\end{aligned}
$$

Set $B=-\left(\left(\partial A_{1} / \partial e\right)\left(\mathrm{d} \sigma^{\prime} / \mathrm{d} e\right)+A_{1}\left(\mathrm{~d}^{2} \sigma^{\prime} / \mathrm{d} e^{2}\right)\right)=-((1+$ $\left.\left.e_{0}\right)^{2} / \gamma_{w}\right)\left[\left(\mathrm{d} \sigma^{\prime} / \mathrm{d} e\right) \cdot(d / d e)\left(K_{d} /(1+e)\right)+\left(K_{d} /(1+\right.\right.$ $\left.e))\left(\mathrm{d}^{2} \sigma^{\prime} / \mathrm{d} e^{2}\right)\right], C=-A_{1}\left(\mathrm{~d}^{2} \sigma^{\prime} / \mathrm{d} e^{2}\right)=-\left(\left(1+e_{0}\right)^{2} K_{d} / \gamma_{w}(1+\right.$ e)) $\left(\mathrm{d}^{2} \sigma^{\prime} / \mathrm{d} e^{2}\right)$; equation (A.1) can be further expressed as follows:

$$
\frac{\partial e}{\partial t}=A \frac{\partial e}{\partial a}+B\left(\frac{\partial e}{\partial a}\right)^{2}+C \frac{\partial^{2} e}{\partial a^{2}}
$$

\section{Data Availability}

The picture data used to support the findings of this study are included within the article.

\section{Conflicts of Interest}

The authors declare that there is no conflict of interests regarding the publication of this paper.

\section{Acknowledgments}

This research was supported by the National Natural Science Foundation of China (No. 51278217), and the support is gratefully acknowledged. We also thank Dr. Qiu Jinwei for the contribution to this manuscript, as well as his ideas.

\section{References}

[1] R. E. Gibson, G. L. England, and M. J. Hussey, "The Theory of one-dimensional consolidation of saturated clays: 1 . Finite nonlinear consildation of thin homogeneous layers," Géotechnique, vol. 17, no. 3, pp. 261-273, 1967.

[2] R. E. Gibson, R. L. Schiffman, and K. W. Cargill, "The theory of one-dimensional consolidation of saturated clays. II. Finite nonlinear consolidation of thick homogeneous layers," Canadian Geotechnical Journal, vol. 18, no. 2, pp. 280-293, 1981.

[3] J. L. Monte and R. J. Krizek, "One-dimensional mathematical model for large-strain consolidation," Géotechnique, vol. 26, no. 3, pp. 495-510, 1976.

[4] T. Tan and R. F. Scott, "Finite strain consolidation - A study of convection," Infection Immunity, vol. 28, no. 3, pp. 64-74, 1988.

[5] M. B. Chopra and G. F. Dargush, "Finite-element analysis of time-dependent large-deformation problems," International Journal for Numerical and Analytical Methods in Geomechanics, vol. 16, no. 2, pp. 101-130, 1992.

[6] P. J. Fox and J. D. Berles, "CS2: A piecewise-linear model for large strain consolidation," International Journal for Numerical and Analytical Methods in Geomechanics, vol. 21, no. 7, pp. 453475, 1997.

[7] P. H. Morris, "Analytical solutions of linear finite- and smallstrain one-dimensional consolidation," International Journal for Numerical and Analytical Methods in Geomechanics, vol. 29, no. 2, pp. 127-140, 2005.

[8] K. H. Xie and C. J. Leo, "Analytical solutions of one-dimensional large strain consolidation of saturated and homogeneous clays," Computers \& Geosciences, vol. 31, no. 4, pp. 301-314, 2004.

[9] C. I. Teh and X. Y. Nie, "Coupled consolidation theory with nonDarcian flow," Computers \& Geosciences, vol. 29, no. 3, pp. 169209, 2002.

[10] S. Hansbo, "Consolidation equation valid for both Darcian and non-Darcian flow," Géotechnique, vol. 51, no. 1, pp. 51-54, 2001.

[11] S. Hansbo, "Deviation from Darcy's law observed in onedimensional consolidation," Géotechnique, vol. 53, no. 6, pp. 601-605, 2003.

[12] K.-H. Xie, K. Wang, Y.-L. Wang, and C.-X. Li, "Analytical solution for one-dimensional consolidation of clayey soils with a threshold gradient," Computers \& Geosciences, vol. 37, no. 4, pp. 487-493, 2010.

[13] H. Ahmadi, H. Rahimi, and A. Soroush, "Investigation on the characteristics of pore water flow during CRS consolidation test," Geotechnical and Geological Engineering, vol. 29, no. 6, pp. 989-997, 2011.

[14] J. Yao, W. Liu, and Z. Chen, "Numerical solution of a moving boundary problem of one-dimensional flow in semi-infinite 
long porous media with threshold pressure gradient," Mathematical Problems in Engineering, vol. 2013, Article ID 384246, 7 pages, 2013.

[15] Y.-B. Deng, G.-B. Liu, R.-Y. Zheng, and K.-H. Xie, "Finite element analysis of Biot's consolidation with a coupled nonlinear flow model," Mathematical Problems in Engineering, vol. 2016, Article ID 3047213, 13 pages, 2016.

[16] F. Slepicka, "Contribution to the solution of the filtration law," International Union of Geodesy and Geophysics, Commission of Subterranean Waters, vol. 1, no. 1, pp. 245-258, 1960.

[17] T. Qi, K.-H. Xie, A.-F. Hu, and Z.-Q. Zhang, "Laboratorial study on non-Darcy seepage in Xiaoshan clay," Journal of Zhejiang University (Engineering Science), vol. 41, no. 6, pp. 1023-1028, 2007 (Chinese).

[18] C.-X. Li, X. Kang-He, W. Kun, and Y. Kun, "One-dimensional consolidation analysis considering exponential flow law for soft clays," China Civil Engineering Journal, vol. 44, no. 8, pp. 111-117, 2011 (Chinese).

[19] J. D. Schmidt and R. A. Westmann, "Consolidation of porous media with non-Darcy flow," Journal of Engineering Mechanics, vol. 99, no. em6, 1973.

[20] R. Walker, B. Indraratna, and C. Rujikiatkamjorn, "Vertical drain consolidation with non-Darcian flow and void-ratiodependent compressibility and permeability," Géotechnique, vol. 62, no. 11, pp. 985-997, 2012.

[21] B. Indraratna, R. Zhong, P. J. Fox, and C. Rujikiatkamjorn, "Large-strain vacuum-assisted consolidation with non-Darcian radial flow incorporating varying permeability and compressibility," Journal of Geotechnical and Geoenvironmental Engineering, vol. 143, no. 1, Article ID 04016088, 2017.

[22] X. Zhao, W. Gong, and H. Yang, "Model for large strain consolidation based on exponential flow law," European Journal of Environmental and Civil Engineering, pp. 1-20, 2019.

[23] K. Lee and G. C. Sills, "The consolidation of a soil stratum, including self-weight effects and large strains," International Journal for Numerical and Analytical Methods in Geomechanics, vol. 5, no. 4, pp. 405-428, 1981.

[24] P. J. Fox, "Coupled large strain consolidation and solute transport.II: Model verification and simulation results," Journal of Geotechnical and Geoenvironmental Engineering, vol. 133, no. 1, pp. 16-29, 2007.

[25] C.-X. Li and K.-H. Xie, "One-dimensional nonlinear consolidation of soft clay with the non-Darcian flow," Journal of Zhejiang University Science A, vol. 14, no. 6, pp. 435-446, 2013.

[26] P. J. Fox and H. Pu, "Enhanced CS2 model for large strain consolidation," International Journal of Geomechanics, vol. 12, no. 5, pp. 574-583, 2012. 


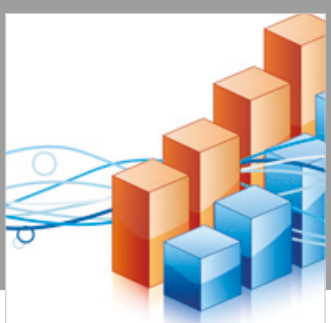

Advances in

Operations Research

\section{-n-m}
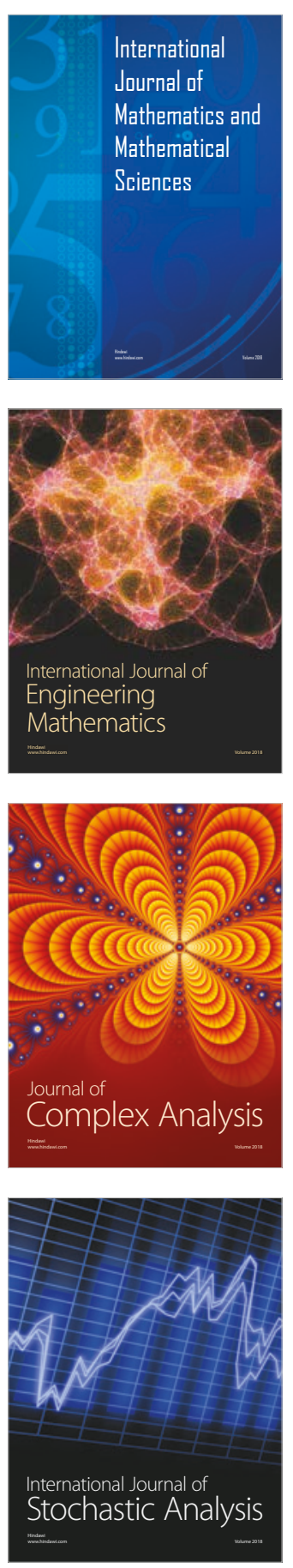
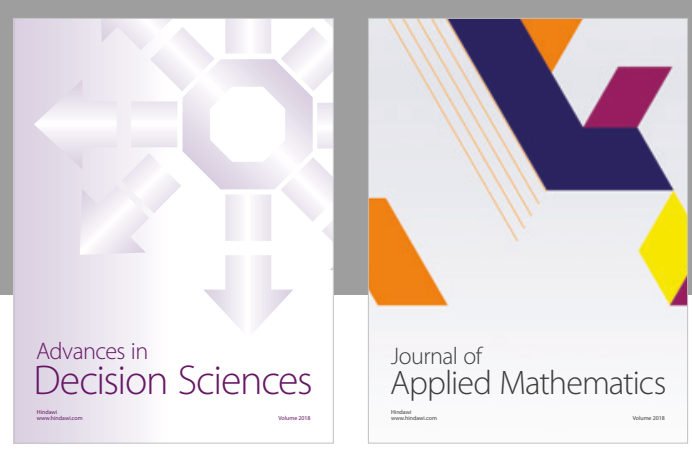

Journal of

Applied Mathematics
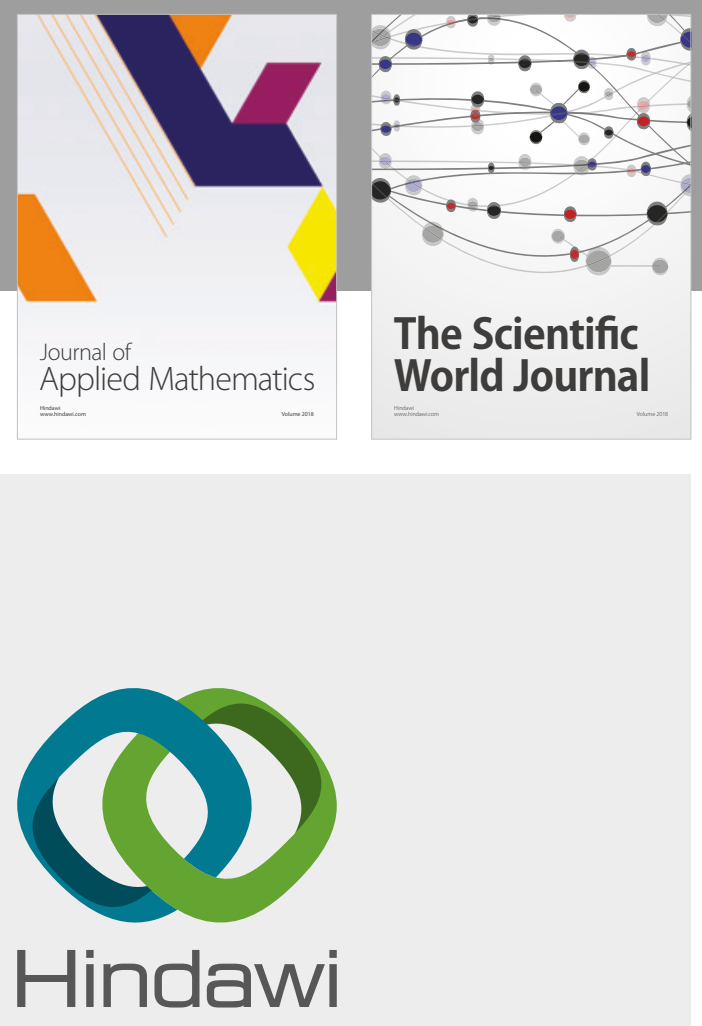

Submit your manuscripts at

www.hindawi.com

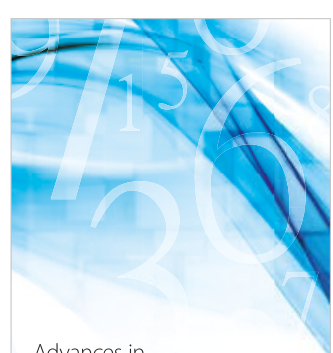

Advances in
Numerical Analysis
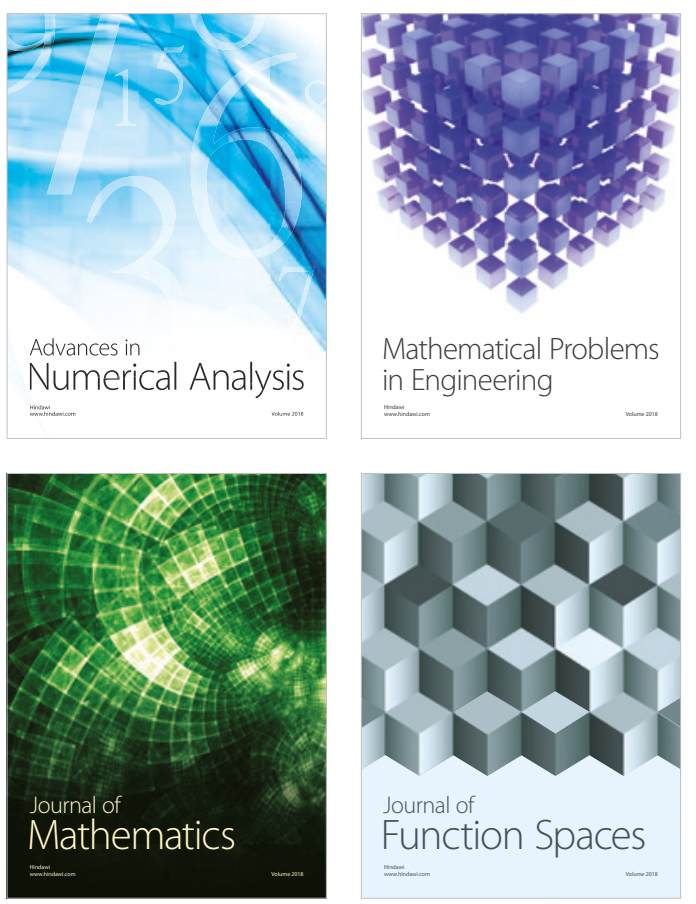

Mathematical Problems in Engineering

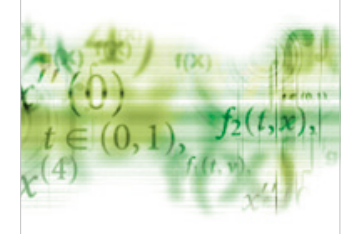

International Journal of

Differential Equations

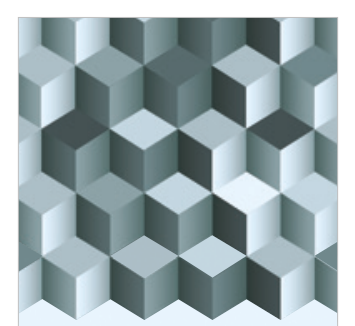

Journal of

Function Spaces

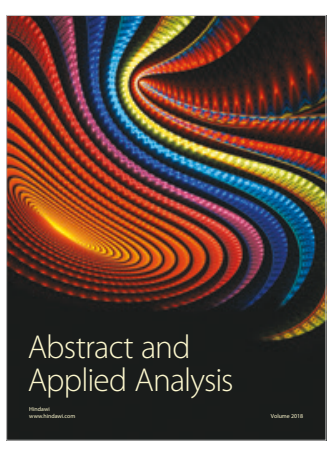

The Scientific

World Journal

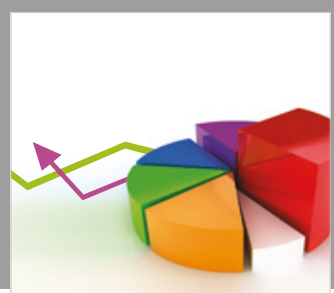

Journal of

Probability and Statistics
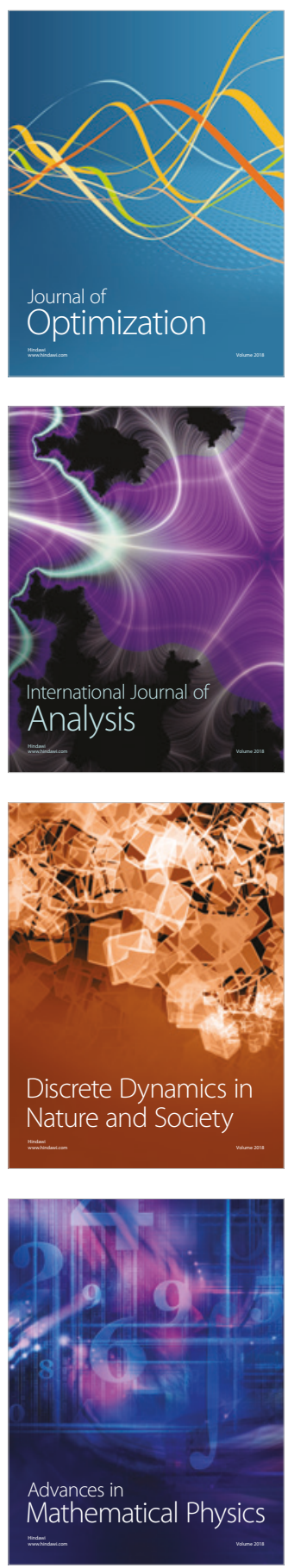